\title{
The Wuhan Botanical Garden - Aquatic Plants Collection ${ }^{(1)}$
}

YANLING LIU(2); MEI LIN(2); WU KAI(2)

E ANTONIO FERNANDO C. TOMBOLATO(3)
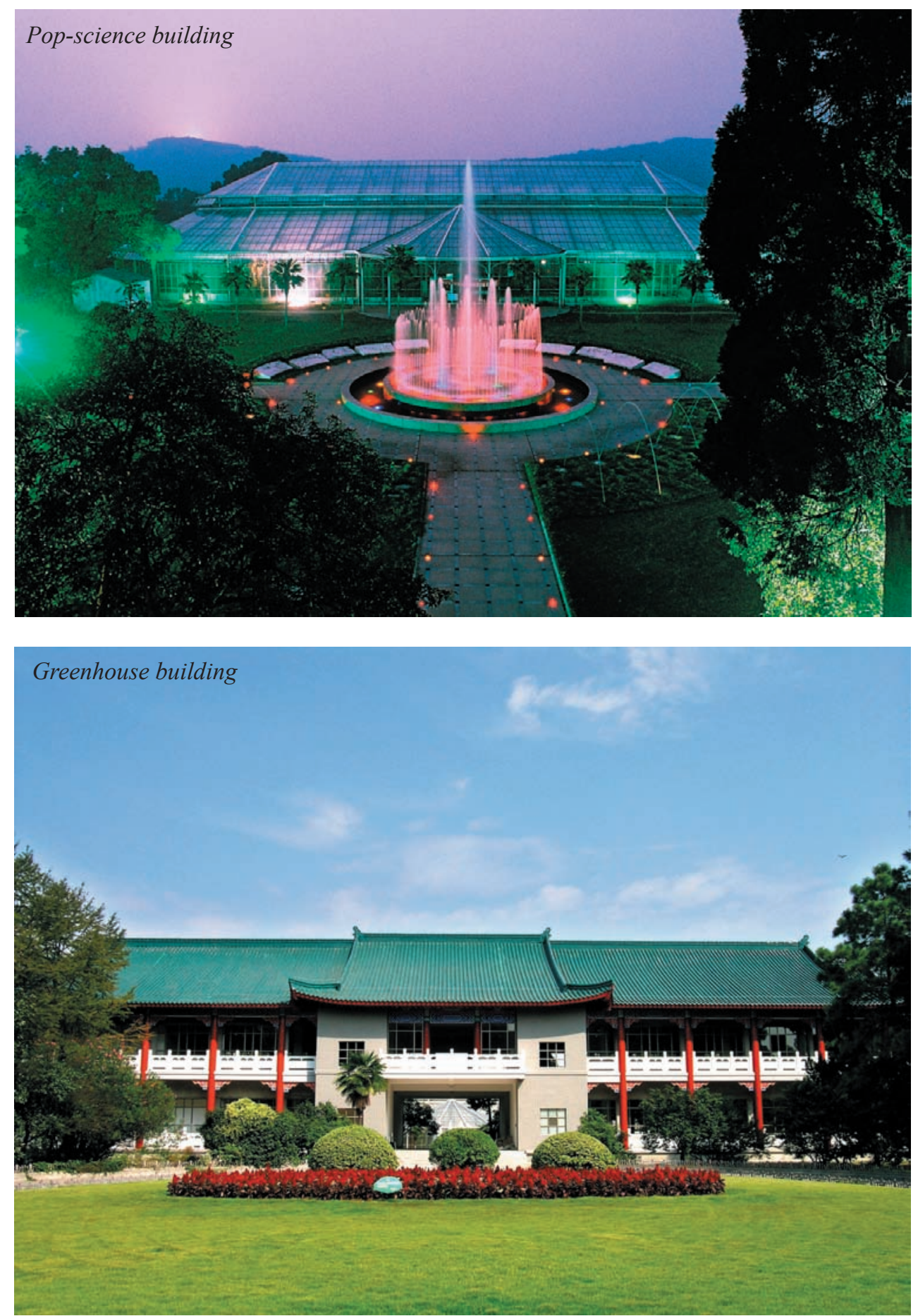

${ }^{(1)}$ This project was supported by the National Natural Science Foundation of China (Project nr. 30671474)

(2)Wuhan Botanical Garden, the Chinese Academy of Science, Moshan, Wuchang, 430074, Wuhan, Hubei Province, China. E-mail: shiliu@rose.whiob.ac.cn

${ }^{(3)}$ Instituto Agronômico, IAC Botanic Garden, Campinas, SP, Brazil. 


\section{INTRODUCTION OF THE WUHAN BOTANICAL GARDEN}

Wuhan Botanical Garden of the Chinese Academy of Sciences (WBG/CAS) was founded in 1956 as a botanical research, education and conservation institution. The Garden is strategically located in the Wuhan City basing on the distinct flora with transitional characteristics from south to north in China. Over the past four decades, WBG/CAS has done extensive research on plant systematics, plant ecology, plant genetics, conservation genetics, aquatic plant biology and economic botany. The research has made significant contributions to the new knowledge of plant sciences, biodiversity conservation, environmental protection, and sustainable utilization of plant resources, hence national economy and quality of life in China. WBG/CAS has become one of the prominent botanical research institutions in China.

As one of the national strategic reserve of plant resources, the Garden covers an area of 70 hectares. It houses the world's largest genetic pool of kiwifruit and largest collections of aquatic plants in East Asia. The Garden also has two satellite gardens, the Three Gorges Botanical Garden in Yichang City and the Rare and Endangered Plant Transition Preservation Site in Huangpi District of Hubei Province. In support of its missions, the Garden maintains a documented and labeled collection of living plants of 7,000 species, and serves as one of the National Science Education Bases. The goal is to add, in 3-5 years, 3,000 new species, highering this garden conservation into with 10,000 species.

There are more than 200 staffs in WBG/CAS, half of which are scientific and technical personnel. The recent CAS "Knowledge Innovation" projects has mandated the CAS/ WBG to research on the conservation genetics, sustainable use of genetic resources, aquatic botany, inland aquatic vegetation restoration, agroforestry, ecosystem management, and national strategic genetic resource reserve. WBG/CAS offers graduate programs leading to Doctor of Philosophy and Master of Science in both Botany and Plant Ecology.

\section{THE AQUATIC PLANTS COLLECTION}

Vascular plant has 87 families, 407 genera belong to the aquatic plant, in the subphylum pteridofita there are 11 genera and 9 families belong to aquatic plants. The Gymnosperma does not have aquatic species, moreover according to the known fossil evidence, also did not exist in the past. In the Magnoliatae (angiosperm) 78 families and 396 genera belong to aquatic plant. But in our country, approximately 65 families and 170 genera vascular plant belong to the aquatic plants. In the Pteridophyta, the aquatic plants are included in 7 genera and 7 families. According to the above data, our final goal for conservation in the aquatic plant's garden is to keep a collection of 5,000 populations of 500 living aquatic species. Among them, 400 are native aquatic plants, in a total of 3,000 populations, and 100 exotic species, equal to 2,000 populations.

The garden is located in Central China and engages in the investigation on aquatic vegetations, and explores the regions such as the Zhejiang, Jiangsu, Jiangxi, Sichuan, Yunnan, Guizhou, Inner Mongolia, Hebei, Jilin, Heilongjiang, Guangxi. We have collected around 70 families of aquatic plants, among them 200 genera and 400 species, including 4 rare and precious aquatic plant species from the 5 included in the "Chinese Plant Red Book": Ottelia acuminata Gagnep. Dandy var. acuminata, Isoetes sinensis Palmer, Isoetes japonica $\mathrm{Al}$. Br. and Oryza rufipogon Griff., besides the Ranalisma Stapf, Ceratopteris Brongn. and some other endangered species. Meanwhile, we were able to protect 550 varieties germplasm resources and 50-60 hybrids, and succeed to select some strains with high economic value, which can be developed in the future and use as new variety (4-5 waterlily varieties which have the water purification function, 1-2 new variety of aquatic ornamental fleur-de-lis and 2-3 species for wetlands). This collection is nowadays the most complete germplasm bank of aquatic plants in size and number of accesses of East Asia.

\section{CARE FACILITY (LAKE, PLOT, GREENHOUSE)}

Aquatic plant introduced from the open areas or other units of conservation, private or public are acclimatized in the ceramic cylinders, mainly to observe their behavior during the summer in the Wuhan area and how they survive the winter. If the plant adapts the Wuhan area climate and reproduce, it will be transplanted to visitor's demonstration area. 


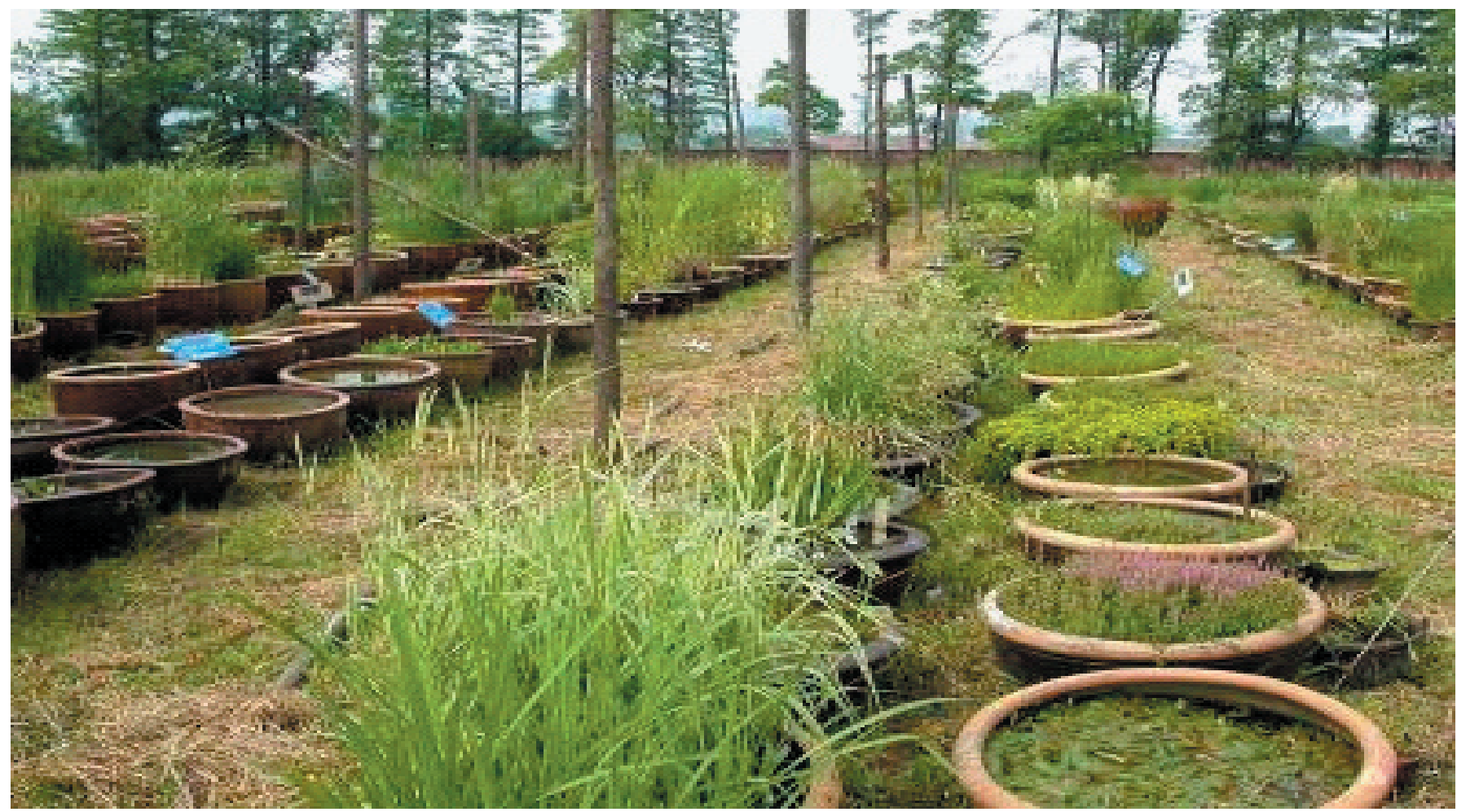

\section{The population exhibition area for the aquatic plants}

An habitat, in an open small reservoir of argillaceous land, in an area of 2,200 $\mathrm{m}^{2}$, exhibits a fully different vegetative form of aquatic plants and emphasizes the community's multiplicity. From the sloping shore to the pond central, water depth gradient's gradual deepening, arranges the sloping shore cover plant community: Rotala rotundifolia and Ludwigia ovalis, emergent aquatic plant community: Typha orientalis and Miscanthus sacchariflorus, hygrophytes community: Sagittaria guyanensis subsp.lappula and Sparganium stoloniferum, floating plant: Pistia stratiotes and Salvinia natans, rootted plants in water bed with floating leaves: Hydrocleys nymphoides and Brasenid schreberi the submerged plant community: Potamogeton lucens, Potamogeton crispus and so on. A total of 110 different ecotypes of aquatic plants fully exhibited to the visitors in compositions and interactions of aquatic plant community.
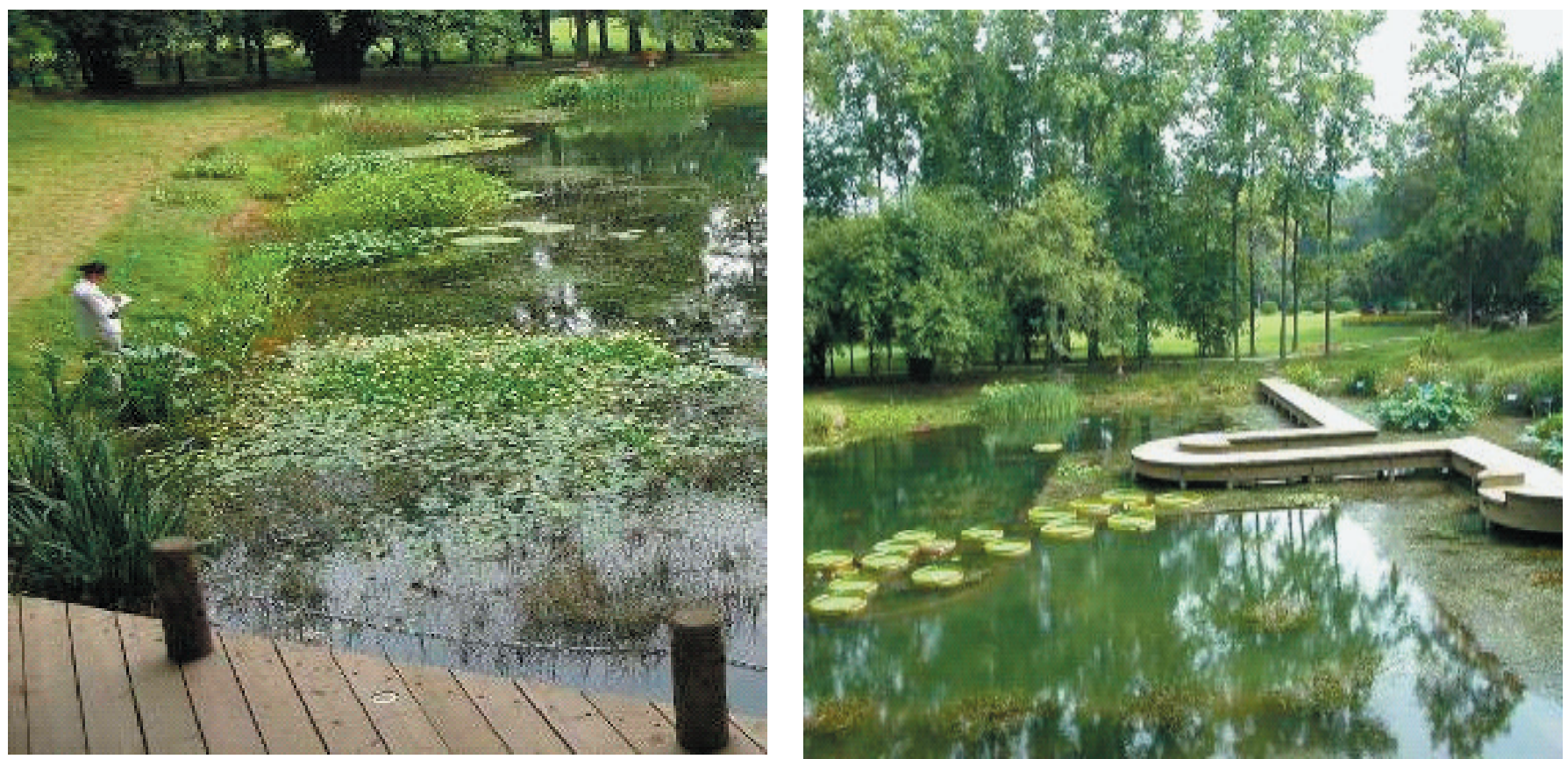


\section{The submerged plants exhibition}

Most of submerged plant adaptiveness and growth speed are quick. They have high ability to purify the water, meanwhile they can form "a submarine forest", They have very important function in the water ecosystem structure and the fresh water resource sustainability. The garden has constructed 142 (different depth of $2 \mathrm{~m}, 1.5 \mathrm{~m}$ and $1 \mathrm{~m}$ ) ponds and 32 large-scale glass demonstration ponds separately according to survival habitats of the submerged plant. This is the first conservation and demonstration of submerged plant area built in China. The submerged plants area occupies a land area of 2,000 square meters, with 56 kinds of submerged plants in conservation, which 35 of these aquatic plants to demonstration and popular science education all the year around.
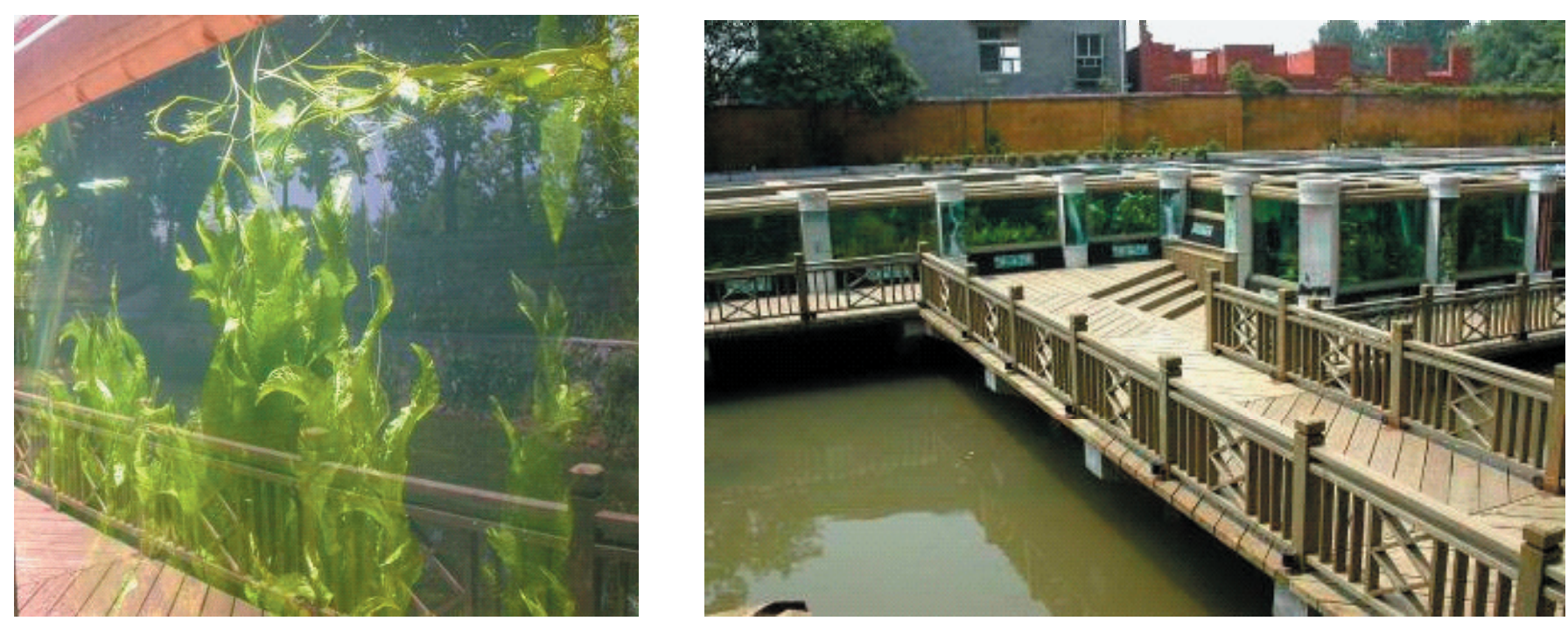

\section{Wetland plant exhibiton area}

The hygrophytes community demonstration area occupies a land area of 5,000 $\mathrm{m}^{2}$. It is the simulation of wetland habitat and demonstrated the hygrophytes community and specially for imminent endangered aquatic plants: Ceratopteris thalictroides, Isoetes sinensis, Oryza rufipogon, Hygroryza aristata, Nymphoides indica and so on. The purpose is the conservation ex situ into a similar natural habitat, to study the genetic biodiversity, reproduction and physiology.

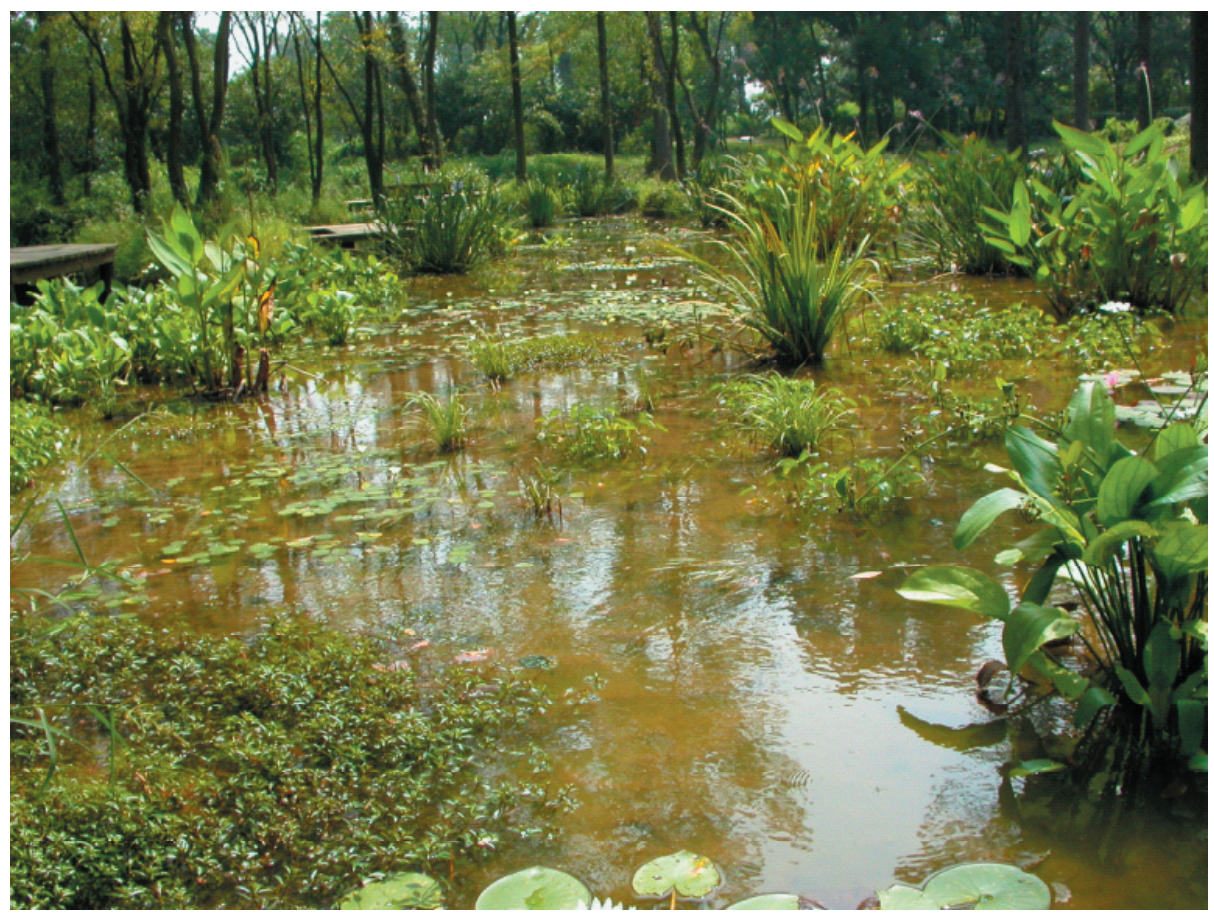




\section{Lake ecological area}

This garden has the approximately 10,000 square meter of deep waters. It is a good demonstration of the rich aquatic plant type and the community structure of Central China waters ecosystem characteristic.

For example, there are some trees communities of amphibious trees like Metasequoia. Phragmites communis and Typha orientalis cover a large area, also has the floating plant waterlily and the submerged plant Ceratophyllum demersum, Hydrilla verticillata var. verticillata, Potamogeton crispus and so on, they all form a rich community structure. This is best experimental location for demonstrating the south China wetlands and the dominated water plants community and seed bank. The aquatic vegetation provides the material for restoration and the eutrophication studies.

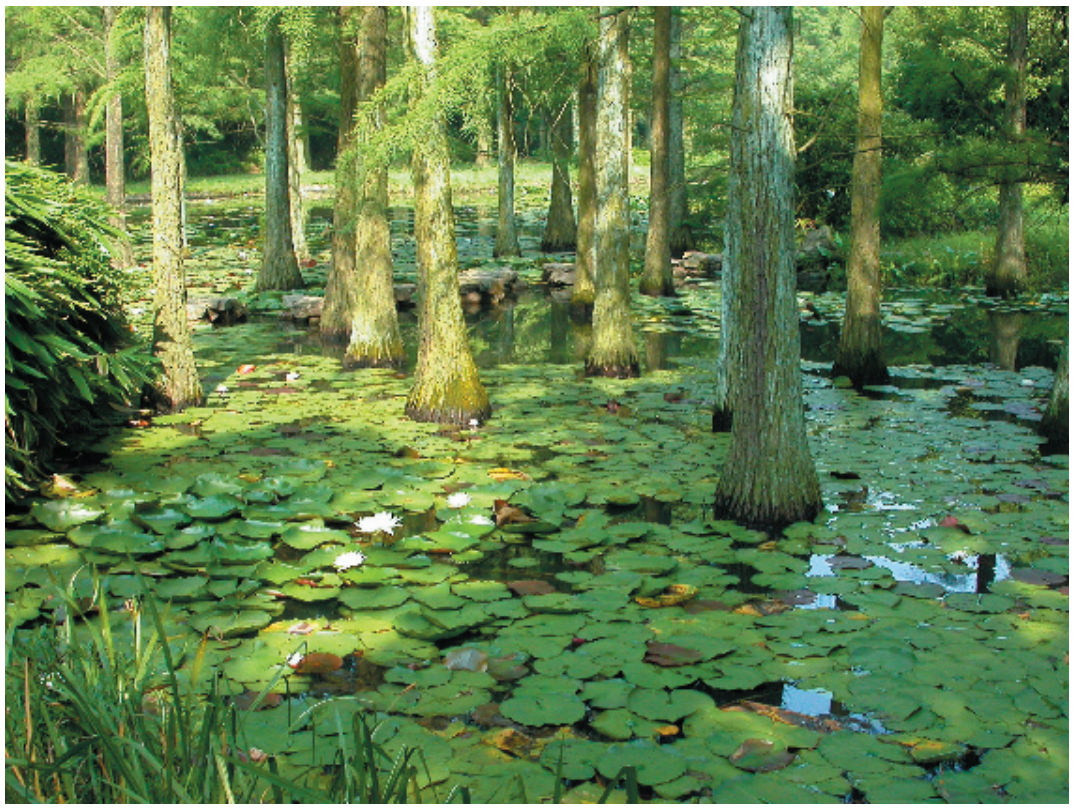

\section{Lotus exhibition area}

The lotus is the Hubei Province's characteristic economical crop, it is also water body beautifies, and one of the first choices plants for water purification. During lotus hybridization emasculation is not need. This is an important theory and the technology, to cultivate some important ornamental value lotus flower varieties and mini varieties which there are more than 100 kinds, like the 'Sino-Japanese Friendship Lotus', the 'Friendship Peony Lotus', 'the "Friendship Red', 'Flying Rainbow', 'Welcoming Guests', 'Purple- Golden Lotus' and so on. '79-A' is a high yield seed production variety and 'Wuhan Botanical Garden nr. 2'is a new root lotus for good edibility. As the main purpose of this area, through the simulation of natural small pond habitat, the lotus variety garden cultivation is in a land area of $5,000 \mathrm{~m}^{2}$ water plant demonstration area.

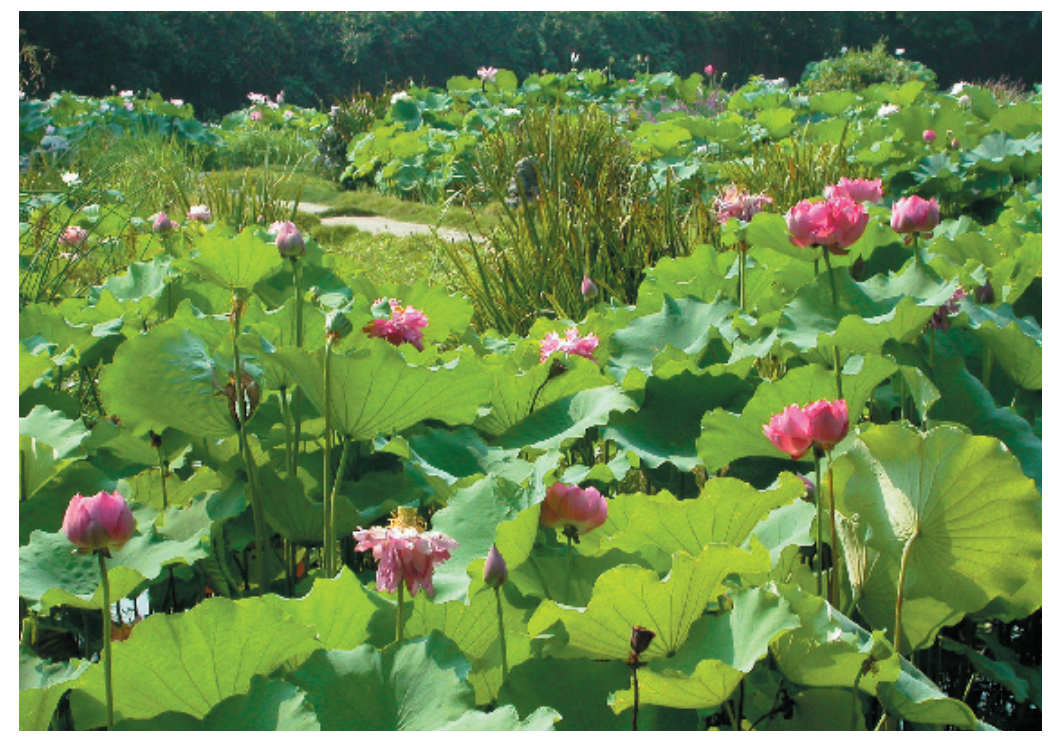




\section{River habitat}

This area simulates a small river habitat. The river total length is 3,000 meters of artificial canals which constructs the ecology suitable to different vegetative forms of aquatic plant growth.

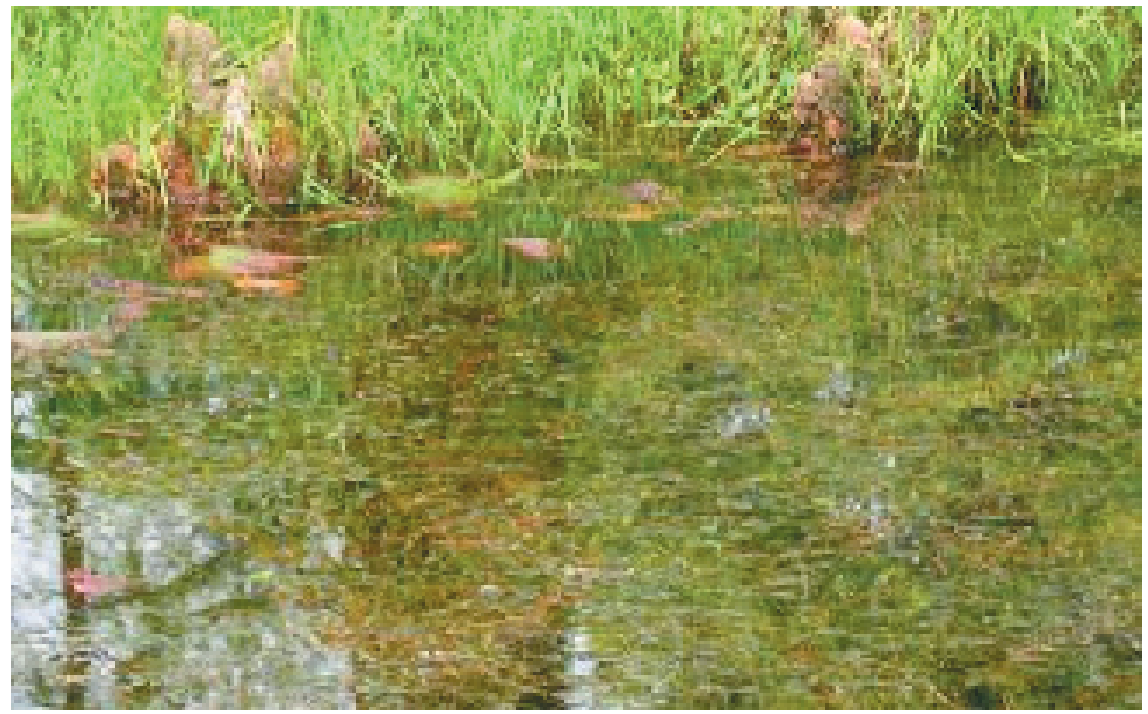

\section{Aquatic plant greenhouse}

This greenhouse is for the native tropical aquatic plants creating a good environment and to enable them set seed to breeding processes and survive during the winter season. There are plants like the Victoria cruziana, tropical waterlily and so on. The tropical aquatic plant area already conserves submerged plants, floating plants, wetland plants and so on in a total of 38 species, and is a scenic spots during winter time.

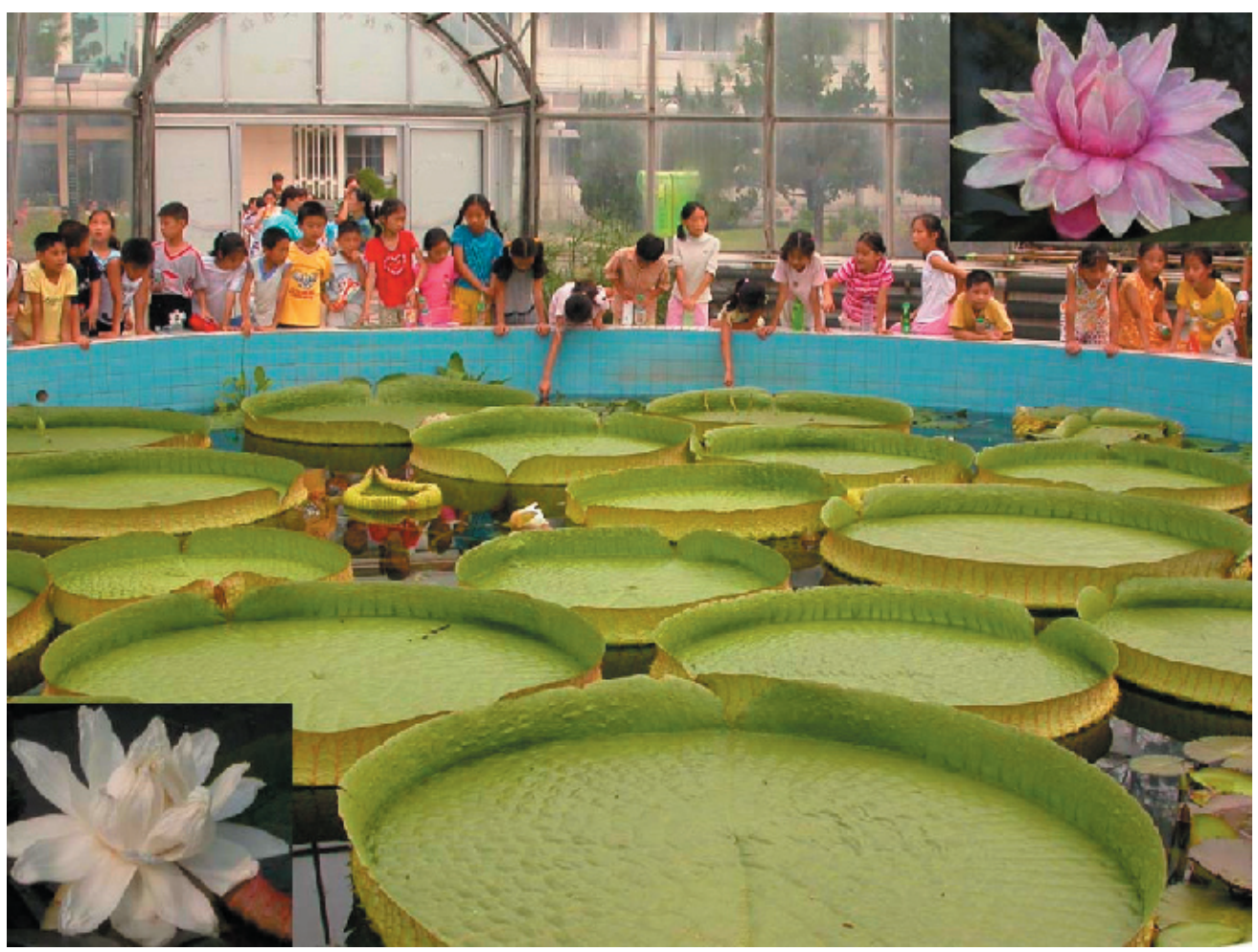




\section{Aquatic plant ecological experiment area}

The aquatic plant ecology experimental plot occupies a land area of 7,200 $\mathrm{m} 2$, separated by the different function's hydrobiology experimental plots, as the large-scale aquatic plant pond, the agitated cisterna, the environment aquatic plant experiment pond and the lake experimental plot. It aims to be a complete structure for aquatic plant biology and the ecology scientific studies, and make it internationally important academic status aquatic plant research center.

\section{Lotus conservation area}

The lotus is a national important aquatic flower, and vegetable. The garden uses ceramics large pots as the main conservation method, and it has collected and preserved around 600 lotus varieties, for the primitive breeding parent material, conservation and research. This is also very important to lotus species taxonomy and breeding.

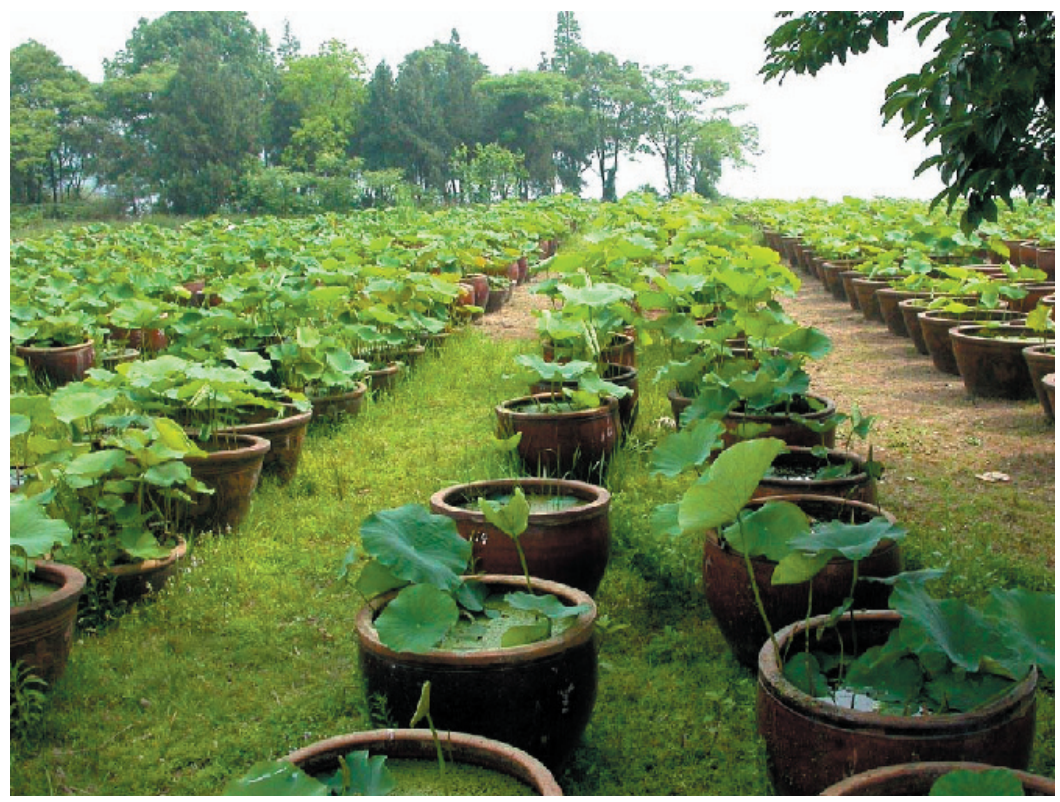

\section{Nymphaea species conservation area}

Although in our country has only 4-5 native Nymphaea species, along with the international flowers and plants market's opening and circulation, our garden has collected and conserved 100 waterlily germplasms (including species and varieties). At present, the $5,000 \mathrm{~m}^{2}$ area for waterlily variety conservation has 96 preservation ponds, 20 parental and hybrid ponds and 6 breeding ponds. There it is also developed plant molecular systematical research, new variety selection breeding and resources bank. It is cultivated 2 cold resistant waterlily varieties, 2 tropical waterlily varieties and 50-60 hybrid idioplasms.

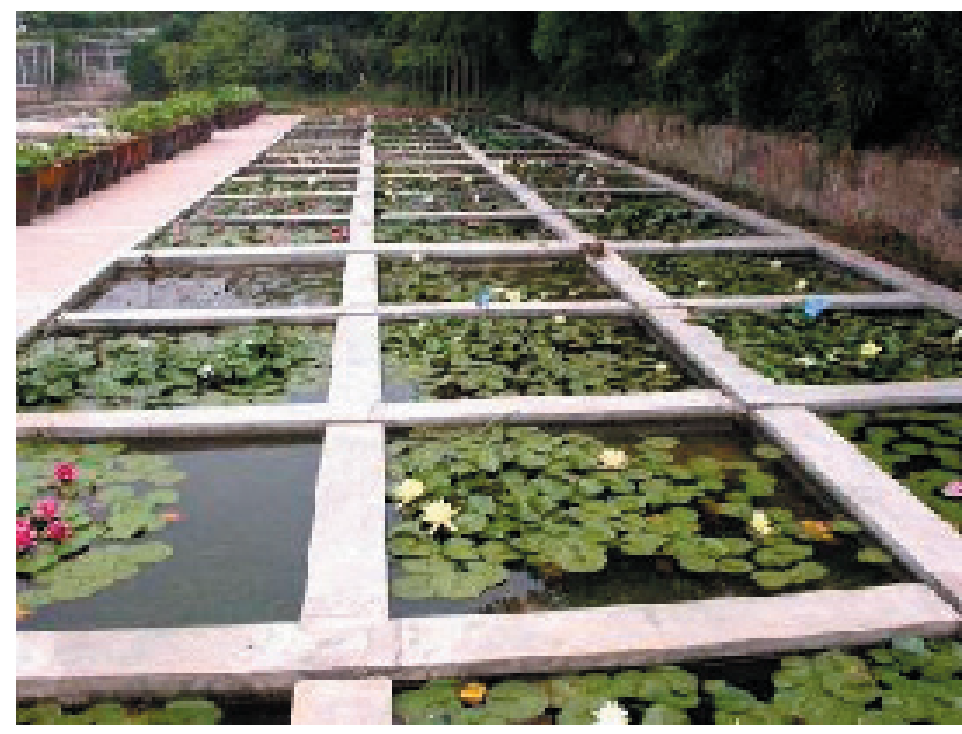




\section{RELATED RESEARCH}

Aquatic plant's research has been a Wuhan botanical garden important discipline domain. We have carried out aquatic plant's resources collection, the classification, the introduction domestication, ex situ conservation, the aquatic economical or decorative plant's heredity breeding and the technical development, as well as aquatic plant direction and protection biology and ecology research.

\section{Breeding and post-breeding of new cultivars}

Use the rich aquatic plant species resources, through wild plant's domestication, fine clone selection, strain's improvement and the selective breeding for the future economy and the social development, also use molecular biology technology. Aquatic plants are also selected to the water purification and improve the agricultural environment and production.

\section{The construction of lotus DNA fingerprinting and core- collection}

Lotus (Nelumbo nucifera) has with rich cultivar resources that are important aquatic economical plants. In China, there are 608 varieties of flower lotus, as well as more than 100 seed and rhizome lotus cultivars. With the increase of lotus varieties and genetic similarity in breeding germplasm, it is essential to develop DNA fingerprinting and core collection of lotus cultivars and germplasm with molecular technology. Lotus materials representing more than $90 \%$ genetic diversity will be sampled for this study, including two species Nelumbo lutea and Nelumbo nucifera, major seed, rhizome, flower and dwarf lotus cultivars, wild lotus, ancient lotus, and other three new breeding varieties performing very well and blooming quite freely in winter of south China. The goal for this project is to characterize each cultivar and establish DNA fingerprinting of lotus germplasm with AFLP, SSR and gene sequences. Some agronomic traits, such as nutritional components of seeds, the shape of carpellary receptacle, the mature period, edibility, shelf-life of fresh lotus rhizome, the internodes number, rhizome shape, and disease resistance, will be combined with molecular data to construct a core collection of lotus germplasm.

\section{Other researches}

There are important fundamental progresses on theory research and application of aquatic plant conservation biology. Also it is a outbreak in aquatic plant restoration ecology by the technology of aquatic plant recover and reconstruction.

\section{SPECIAL EVENTS IN THE YEAR}

Scientific education and public service has been one of the important function of Wuhan botanical garden, CAS. Every year, different kinds of flower, fruits exhibitions and other special activities are hold regularly, which attract the tourist and become the popular science propaganda.

December to March - in the conservation hall The Fashion Orchid Exhibition,

February to April - in the conservation hall and in the open ground The Tulip Flower Show. Nearly 1,000,000 bulbs with more than 60 varieties,

April to May - Rhododendron Exhibition. More than 20 varieties from the Shennongjia wild conservation park

May to November - aquatic flowers and plants exhibition. It is mainly the Lotus, Nymphaea and other aquatic flowers.

In June, WBG jointly with Hubei Province Office manage a project to suppress drugs using opium as example.

In October, the picking activity of The Metropolis Orchard Kiwi Fruit is conducted. 